\title{
The Design of Adaptive Control System of Electric Load Simulation System
}

\author{
CHEN Hao ${ }^{1}$, WU Dingding ${ }^{2}$, RAO Guoxi ${ }^{3}$, ZHAO Xuchang $^{4}$ \\ ${ }^{1,2}$ College of Mechanical and Electrical Engineering, Southwest Petroleum University, Sicuan Chengdu 610500 \\ ${ }^{3,4}$ College of Mechanical, Beijing Jiaotong University, Beijing 100044
}

\begin{abstract}
This paper introduces the ELSS and analyses the structure and working principle of the ELSS. The numerical model of the electric load simulation system is established in this paper. On the basis of it, an adaptive control system is designed to suppress the surplus torque of the system. We obtain the adaptive laws of the system. Finally, through the numerical simulation results verify the validity of the control method.
\end{abstract}

Keywords: ELSS, surplus torque, design, adaptive control, numerical simulation

\section{Introduction}

Load simulation system, can be applied to simulating the load spectrum of air hinge moment of aircraft's control surface under ground experiment conditions ${ }^{[1]}$. Furthermore, electric load simulation system(ELSS) has been widely applied in small and medium-sized or highly accurate simulation owing to its rapid response, control agility and high loading precision ${ }^{[2]}$.

Electric load simulation system is a typical passive torque servo system loaded by the mutual torsion of loading motor and steering gear, in which the rotation of steering gear will have a significant impact on load torque and its resultant torque is called surplus torque. Therefore, the problem that suppressing the surplus torque in ELSS is needed to be addressed as a matter of urgency. Nowadays, a lot of researching results has been produced in the studies on that problem at home and abroad, in which introducing the feed-forward controller into the system based on the structure invariable principle is considered as a relatively effective way ${ }^{[3]-[4]}$. However, this kind of compensation is entirely dependent on an exact numerical model in the interference link. In some system with operating mode changes, it cannot achieve the effective suppression ${ }^{[5]}$. Also, there are other methods to solve the problem such as position synchronization, optimum control and robust control $^{[6]-[13]}$, all of which have certain limitation more or less and cannot be applied effectively on actually engineering project.

In this paper, a designed method that can automatically adapt to the disturbance torque at the inhibition location based on feed-forward control and adaptive control principles will be introduced. This method can make the system adjust the parameters of controller with self-adaptation and suppress the disturbance of surplus torque to improve the output accuracy of torque in the system on condition that actual system parameters change slowly or are unknown partly. By the results of numerical simulation simulation, the effectiveness of this adaptive control system has been confirmed as well in this paper.

\section{The Principle and Numerical Model of ELLS}

In the loading process of steering gear, torque sensor collects the torque values that are actually loaded on bearing rudder shaft. In the same time, encoder collects the collected torque values and steering angles, computer will be ordered to calculate the given torque values of loading motor and output the result to motor actuator. The working principle diagram of ELLS is shown in Figure 1.

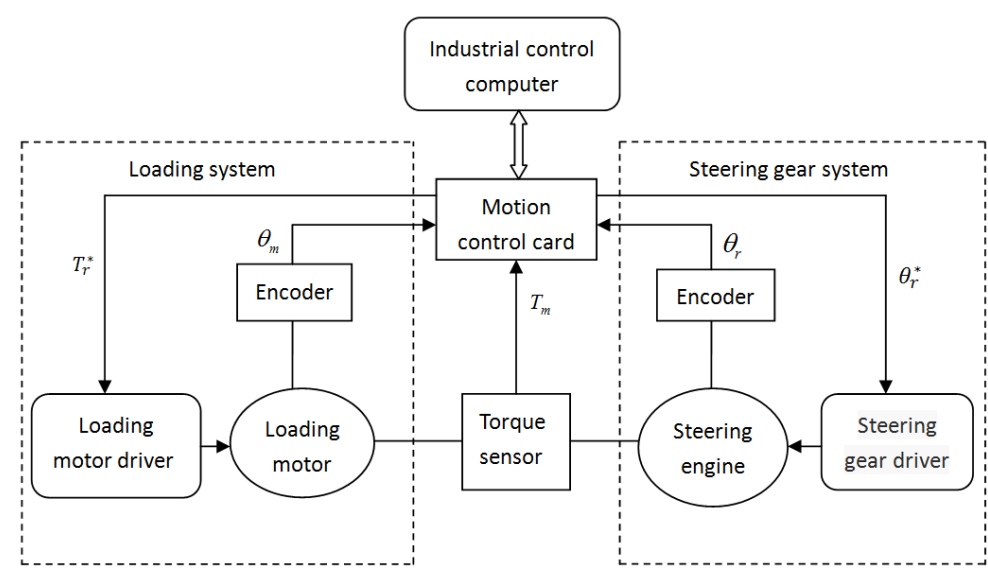

Figure 1: Working principle diagram of ELSS

Volume 5 Issue 7, July 2016 www.ijsr.net 


\section{International Journal of Science and Research (IJSR) \\ ISSN (Online): 2319-7064}

Index Copernicus Value (2013): 6.14 | Impact Factor (2015): 6.391

Through analyzing the working principle of load servo motor and the mechanism of torque generation, we can draw the numerical model of load simulation system, as shown in Figure 2. $U(s)$ is the control quantity of the controller output voltage. $L_{m}$ and $R_{m}$ are the working inductance and resistance of the loading motor. $I_{m}$ is the armature current. $K_{T}$ is the torsion coefficient of the motor. $T_{m}$ is electromagnetic torque of the loading motor. $T_{L}$ is the actual output torque of the loading system. $J_{m}$ is the equivalent moment of inertia converted onto the loading motor shaft. $\omega_{m}$ is the speed of the loading motor. $\theta_{m}$ is the rotation angle of the loading motor. $\theta_{r}$ is the steering angle. $K_{f}$ is the torsional stiffness of the torque sensor. $K_{e}$ is the back electromotive force of the motor.

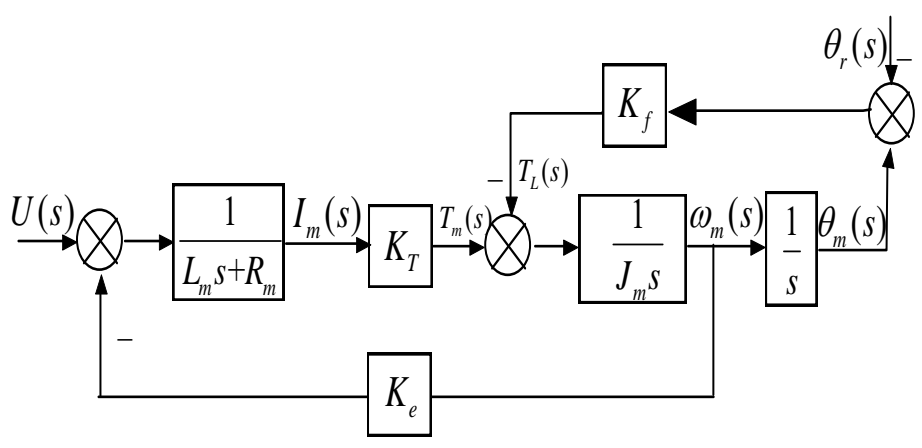

Figure 2: Numerical model of ELSS

\section{The Adaptive Control Design}

The adaptive control is an adaptive control strategy. Since it was put forward by the professor of MIT in the late 1950s, a variety of different control schemes of it had emerged ${ }^{[13]-[16]}$. A new control method is designed in this study based on the model reference adaptive system(MRAS) and combining the feed-forward control compensation principle. The basic structure of model reference adaptive system is shown in Figure 3. The control object is to make the deviation $(e)$ from the actual output $\left(y_{p}\right)$ and the output of the reference model $\left(y_{m}\right)$ equal to 0 . When the controller and controlled object change making the actual output of the system deviate from the target output, that is to say, the actual output of the system is not equal to the target output, the deviation signal will be input to the adaptive mechanism that can generate a regulation scheme in accordance with the pre-established adaptation law and change the parameters of the controller to make the main circuit tend to be consistence with the reference model and the actual output approximate to the object reference output.

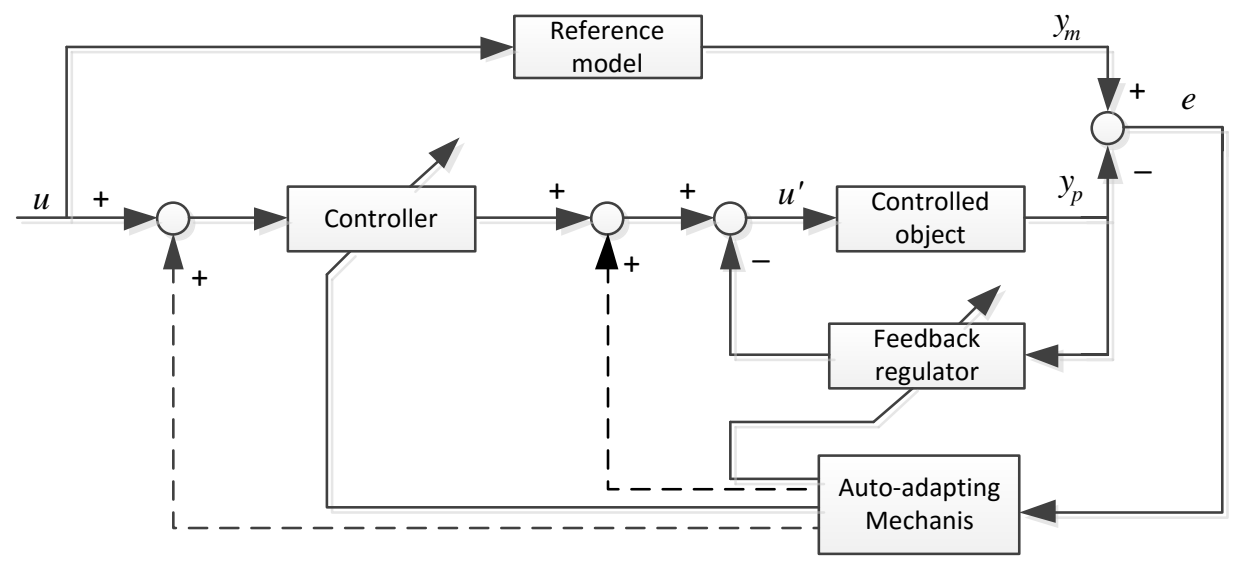

Figure 3: Basic structure of MRAS

According to the characteristics of the controlled object of ELSS, the state-space numerical model of the reference model is

$$
\left\{\begin{array}{l}
\dot{x}_{\mathrm{m}}=A_{\mathrm{m}} x_{m}+B_{\mathrm{m}} u \\
y_{m}=\mathrm{C}_{\mathrm{m}} x_{\mathrm{m}}
\end{array}\right.
$$

The state space of the actual system is described as

$$
\left\{\begin{array}{l}
\dot{x}=A x+B u \\
y_{p}=C x
\end{array}\right.
$$

Figure 4 is the adaptive control system diagram of the design. In this design, on account of the position disturbance of servo motor in loading motor, the actuator motion disturbance is considered as a part of the controlled model in the system when designing the controller. Also, a separate control link has been designed aimed at the position disturbance of bearing motor and feed-forward controller been introduced into the self-reference control system of conventional model. Due to the introduction of the angular velocity of the position motion and for having a corresponding adjustable controller to adapt to this change, we have added a differential term to the feed-forward controller of the system and introduced new controller 


\section{International Journal of Science and Research (IJSR) \\ ISSN (Online): 2319-7064}

Index Copernicus Value (2013): 6.14 | Impact Factor (2015): 6.391

parameters, after which the adaptive mechanism will adjust the parameters of the controller with differential term through the angular velocity of the motor shaft to generate a compensation to reduce the surplus torque. As a result of the surplus torque being related to the angular velocity and angular acceleration of the shaft and the majority of the surplus torque caused by the angular velocity in the middle and low frequency, the differential terms will be introduced as the compensation for angular velocity. So eventually the main controller is designed as a proportional controller and the feed-forward compensation controller as a proportional-derivative controller.

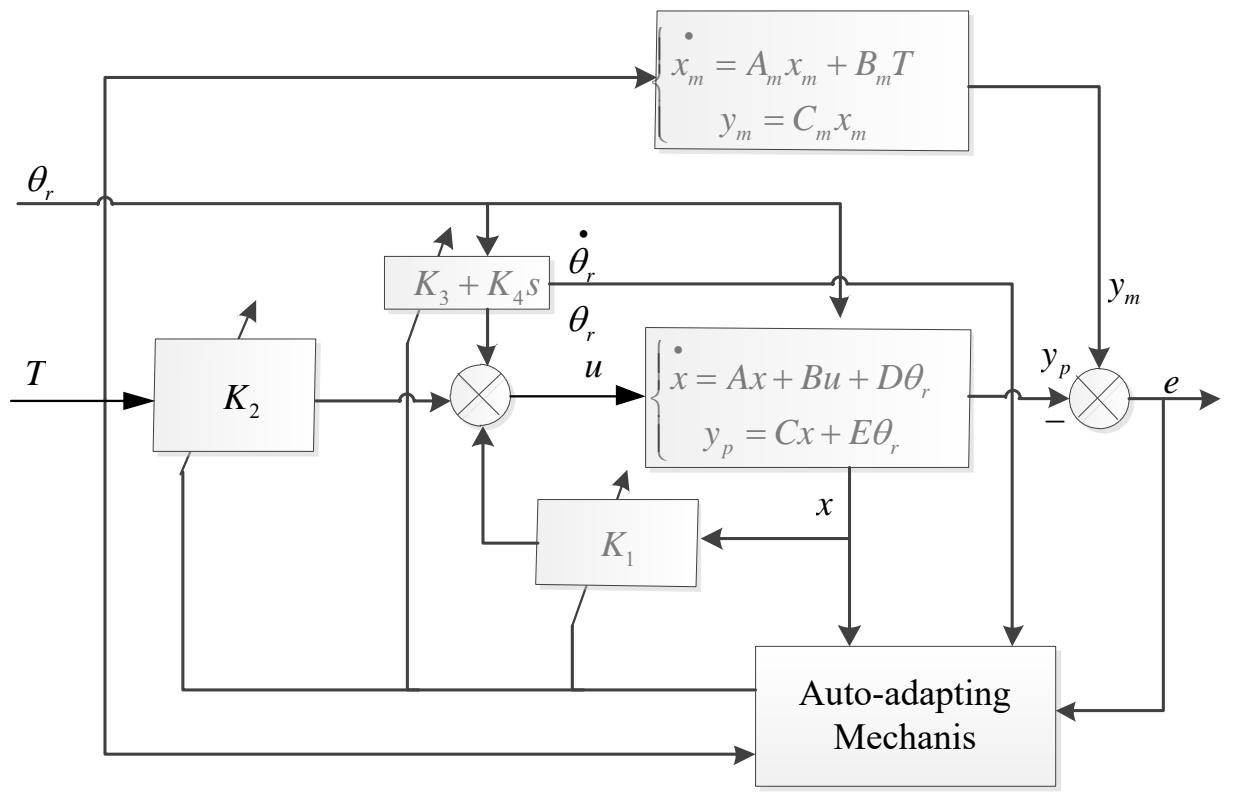

Figure 4: Adaptive control system diagram

At this time the controlling quantity of the system is

$$
u=K_{1} x+K_{2} T+K_{3} \theta_{r}+K_{4} \dot{\theta}_{r}
$$

The output error of the system is

$$
e=y_{m}-y_{p}
$$

The first derivative of the system error is

$$
\dot{e}=C_{m} \dot{x}_{m}-C \dot{x}-E \dot{\theta}_{r}
$$

Let matrix revertible and state-space equation (1) and (2) and control equation (3) used to the above formula, and differential equation of system error will be presented as

$$
\begin{gathered}
\dot{e}=\Phi e+\Phi_{1} x+\Phi_{2} T+\Phi_{3} \theta_{r}+\Phi_{4} \dot{\theta}_{r} \\
=C_{m} A_{m} C_{m}^{-1} e+\left(C_{m} A_{m} C_{m}^{-1} C-C B K_{1}-C A\right) x \\
+\left(C_{m} B_{m}-C B K_{2}\right) T \\
+\left(C_{m} A_{m} C_{m}^{-1} E-C B K_{3}-C D\right) \theta_{r} \\
+\left(-E-C B K_{4}\right) \dot{\theta}_{r}
\end{gathered}
$$

It can be seen from the above that by increasing the control of angular velocity, we can construct a simple Lyapunov function to make generalized error converging asymptotically and obtain the adaptive laws for parameters of the controller $K_{1}, K_{2}, K_{3}$ and $K_{4}$.

Defining the system Lyapunov function as

$$
V=\frac{1}{2}\left(p e^{2}+\Phi_{1} \Phi_{1}^{2}+\Phi_{2}^{2}+\Phi_{3}^{2}+\Phi_{4}^{2}\right)
$$

In equation (7), $p>0$, then $V>0$, so the Lyapunov function is positive definite.

The first derivative of the Lyapunov function is

$$
\dot{V}=p e \dot{e}+\Phi_{1} \dot{\Phi}_{1}^{\mathrm{T}}+\Phi_{2} \dot{\Phi}_{2}+\Phi_{3} \dot{\Phi}_{3}+\Phi_{4} \dot{\Phi}_{4}
$$

Plugged the differential equation of system error (6) into equation (8), we get

$$
\begin{array}{r}
\dot{\mathrm{V}}=p \Phi e^{2}+\left[\left(p e x+\dot{\Phi}_{1}^{\mathrm{T}}\right) \Phi_{1}+\left(p e T+\dot{\Phi}_{2}\right) \Phi_{2}+\left(p e \theta_{r}+\right.\right. \\
\left.\left.\dot{\Phi}_{3}\right) \Phi_{3}+\left(p e \dot{\theta}_{r}+\dot{\Phi}_{4}\right) \Phi_{4}\right]
\end{array}
$$

Let the last item of the above formula equal to zero

$$
\begin{gathered}
\left(p e x+\dot{\Phi}_{1}^{\mathrm{T}}\right) \Phi_{1}+\left(p e T+\dot{\Phi}_{2}\right) \Phi_{2}+\left(p e \theta_{r}+\dot{\Phi}_{3}\right) \Phi_{3}+ \\
\left(p e \dot{\theta}_{r}+\dot{\Phi}_{4}\right) \Phi_{4}=0
\end{gathered}
$$

Due to the stability of the system reference model, the eigenvalue $A_{m}<0$. From this we know $\Phi<0$. Therefore $\dot{\mathrm{V}}<0$, and the function $\dot{\mathrm{V}}$ is negative semi-definite. Lyapunov function is positive definite and The first derivative of the Lyapunov function is negative semi-definite, which satisfies the Lyapunov stability theorem and the system is stable. At this time the error converges to 0 and the adaptive law is

$$
\begin{gathered}
\dot{\Phi}_{1}=-p e x^{T} \\
\dot{\Phi}_{2}=-p e T \\
\dot{\Phi}_{3}=-p e \theta_{r} \\
\dot{\Phi}_{4}=-p e \dot{\theta}_{r}
\end{gathered}
$$




\section{International Journal of Science and Research (IJSR) \\ ISSN (Online): 2319-7064}

Index Copernicus Value (2013): 6.14 | Impact Factor (2015): 6.391

\section{The Analysis of Numerical Simulation}

To verify the effectiveness of the adaptive control system, the structure diagram of the system is constructed on the basis of Simulink in this study. Also, computer simulation is made for the system under the condition that the sinusoidal frequencies of steering gear when it's in motion are $1 \mathrm{~Hz}$, $5 \mathrm{~Hz}$ and $10 \mathrm{~Hz}$ respectively. System related parameters are set as shown in Table 1.

Table 1: System related parameters

\begin{tabular}{|c|c|}
\hline Related parameters & Numerical value \\
\hline Proportionality factor $P$ & 1000 \\
\hline Initial value of the input $(\mathrm{Nm})$ & 0 \\
\hline Initial value of the output $(\mathrm{Nm})$ & 0 \\
\hline Initial value of state variable $X_{\mathrm{m}}$ & 0 \\
\hline Initial value of adjustable gain $K_{1}$ & 0 \\
\hline Initial value of adjustable gain $K_{2}$ & 0 \\
\hline Initial value of adjustable gain $K_{3}$ & 0 \\
\hline Initial value of adjustable gain $K_{4}$ & 0 \\
\hline Moment of inertia $\left(\mathrm{Kg} \cdot \mathrm{m}^{2}\right)$ & 0.01 \\
\hline Amplitude of the input torque $(\mathrm{Nm})$ & 6 \\
\hline Motion amplitude of steering gear $(\mathrm{rad})$ & $\pi / 6$ \\
\hline Simulation step size & 0.001 \\
\hline
\end{tabular}

Figure 5 are the torque output and tracking error of adaptive control system. It can be known from the diagram (a) that when the motion frequency of steering gear is $1 \mathrm{~Hz}$ and the regulation has just begun, the initial tracking error is very large because of the initial settings have had a value of 0 . With the constant sampling adjustment of the adaptive law, tracking error will decrease and eventually tend to 0 . At the moment the system is adjusted to the error of 0 with a time of about $10 \mathrm{~s}$

The change rule of tracking error of the system is same when the motion frequency of steering gear is $5 \mathrm{~Hz}$ or $10 \mathrm{~Hz}$ as it is $1 \mathrm{~Hz}$ that tracking error decreases and eventually tends to 0 . But it will take 11s for the system to be adjusted when the frequency is $5 \mathrm{~Hz}$ and $12 \mathrm{~s}$ when the frequency is $10 \mathrm{~Hz}$, as shown in figure (b) and figure (c). Through comparison, we can know that the higher the motion frequency of steering gear is, the longer the adjustment time of tracking error of the system is.
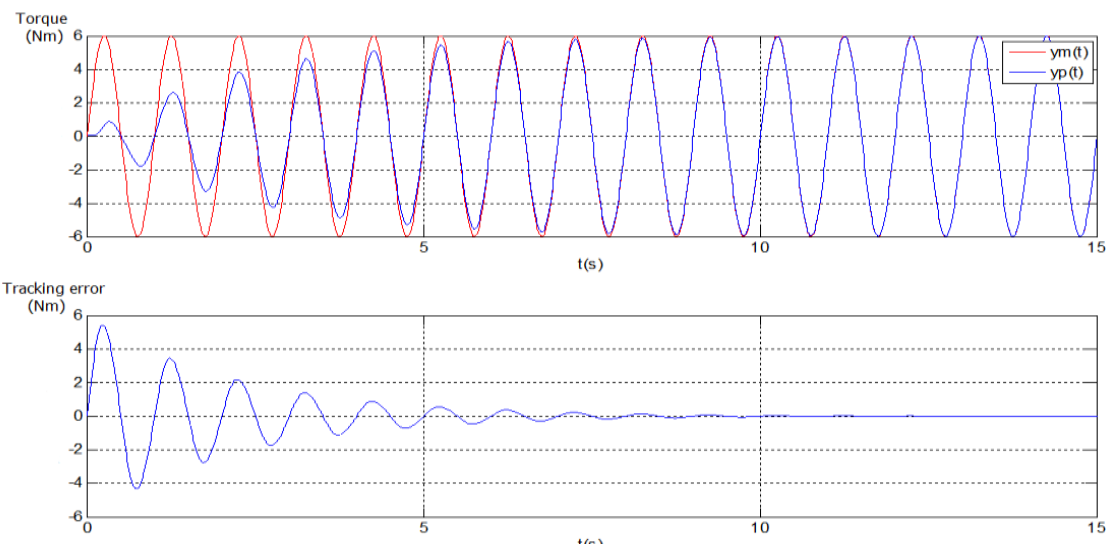

(a) $1 \mathrm{~Hz}$
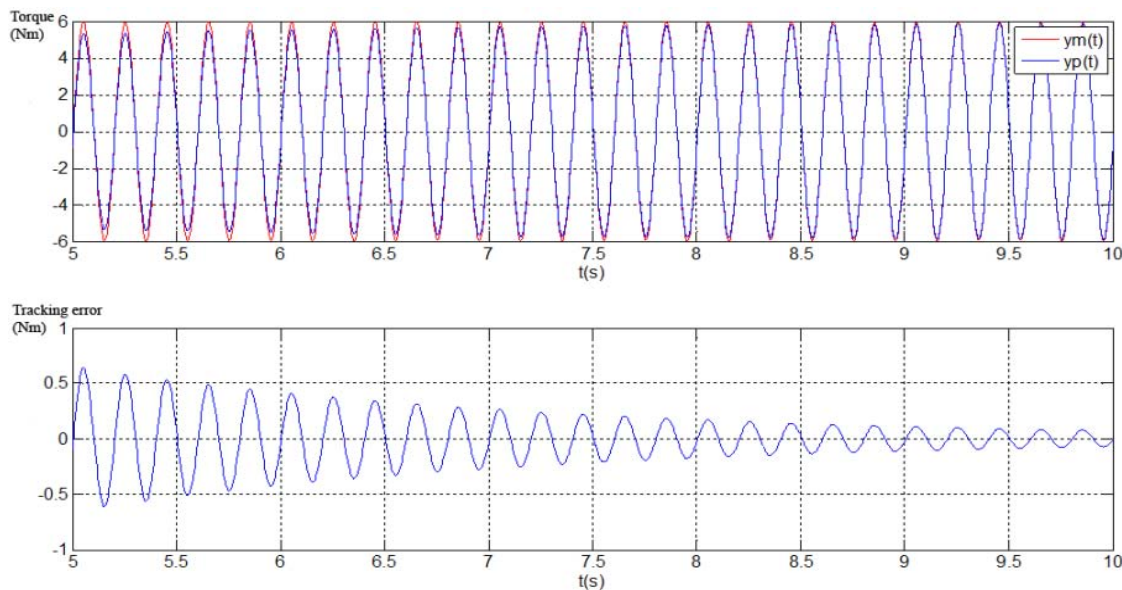

(b) $5 \mathrm{~Hz}$

Volume 5 Issue 7, July 2016

www.ijsr.net

Licensed Under Creative Commons Attribution CC BY 
International Journal of Science and Research (IJSR)

ISSN (Online): 2319-7064

Index Copernicus Value (2013): 6.14 | Impact Factor (2015): 6.391
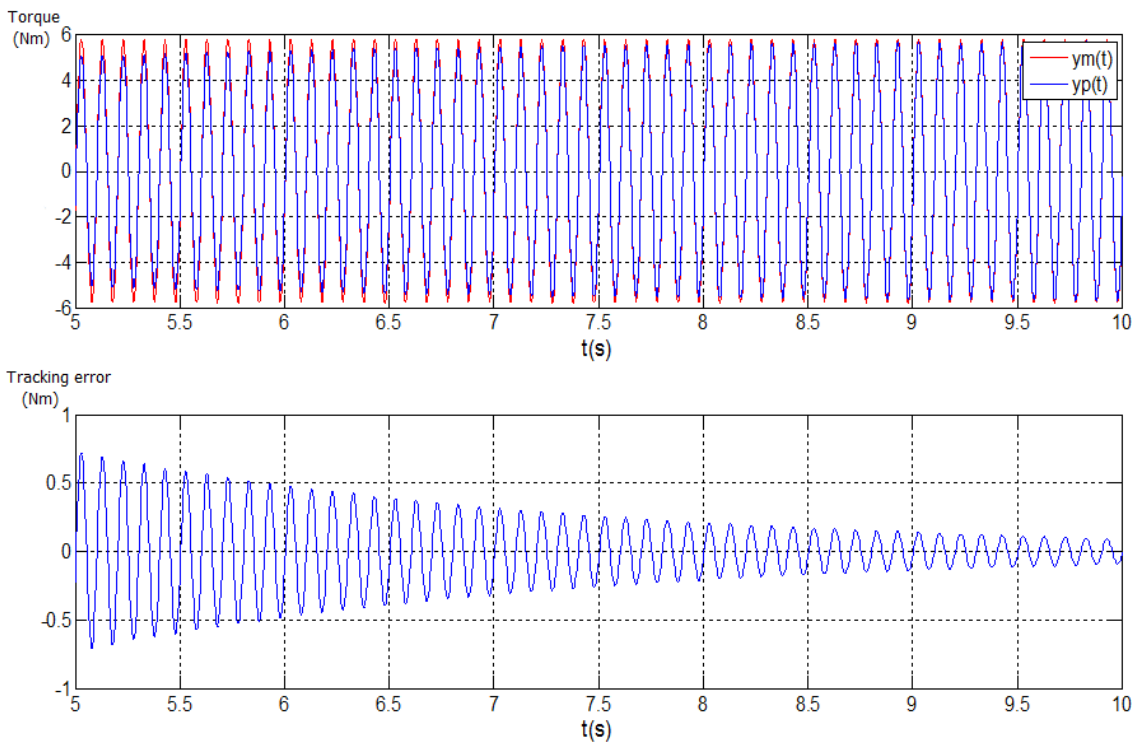

(c) $10 \mathrm{~Hz}$

Figure 5: The torque output and tracking error of adaptive control system

The computer simulation of the adaptive system shows that the effectiveness of the adaptive control system to suppress the loading error. It can stabilize the system in the ideal output state through the output of the reference model in the small changes that the actual parameters of the system unknown or gradient. Also, it has a strong adaptability and robustness.

\section{Conclusion}

In this paper, the structure composition and working principle of the electric load simulation system are analyzed and the numerical model of ELSS is given. Also, an adaptive control system that can track the torque input and suppress surplus torque effectively is designed and the adaptive law of it is obtained. Moreover, the effectiveness of the system suppressing the load error is proved by computer simulation analysis and experiment.

\section{References}

[1] Kaboli, S.; Zolghadri, M.R.; Haghbin, S.; Homaifar. Effects of the Flux Value on the Torque Ripple of the Direct Torque Controlled Induction Motor Drives Determination $[\mathrm{J}]$. A Power Electronics and Drive Systems, 2003, (1): 439 - 444

[2] WANG Xin, FENG Dong-zhu. Experimental research on DC load simulator test bed with elastic $\operatorname{rod}[\mathrm{J}]$. Journal of electrical machines and control, 2012, 9(16):91-94.

[3] Springob, L, Holtz, J. High-Bandwidth Current Control for Torque-Ripple Compensation in PM Synchronous Machines[J]. Industrial Electronics, 2011, 45(5):713 721.

[4] Quang Truong Dinh, Kyoung Kwan Ahn, Jong Il Yoon. Introduction to Quantitative Feedback Theory For Robust Force Control of Load Simulator[C]. Communications and Electronics Second International
Conference.2008: 42 - 47

[5] C. Ramden, A. Jansson and J. O Palmberg. Design and Analysis of a Load Simulator for Testing Hydraulic Valves[C]. Fluid Power Engineering Challenges and Solutions, 10th Bath International Fluid Power Workshop, Edited by C.R.Burrows and K. A.Edge. Sept.10 12, 2012.

[6] YAO jianjun, WANG Xiancheng, WU zhenshun. Control Applied In Electro-hydraulic Servo System with ANN[J].Chinese Journal of Mechanical Engineering. Vol.19/no.1. 2006: 32-36

[7] Yang junyou, He Guofeng, Gui Jiefan. Sliding mode Variable-structure direct thrust control of PMLSM using SVM[A].ICEMS[C].Nanjing, China, 2005: $1655-1658$

[8] N.Niksefat, N.Sepehri. Design and Experimental Evaluation of a Robust Force Controller for an Electro-hydraulic Actuatorvia Quantitative Feedback Theory $[\mathrm{J}]$. Control Engineering Practice,2011, Vol.8 .pp.1335 1345.

[9] Navid Niksefat, Nariman Sepehri. Designing Robust Force Control of Hydraulic Actuators Despite System and Environmental Uncertainties[J]. IEEE Control Systems Magazine, April 2012, pp. 66 77.

[10] Y. Eto, N.Endo. Real-time simulator for torque split contol system[J]. JSAE Review, Oct. 1995, 16(4):391-395.

[11] Hyung-Min Ryn, et al. Dynamic load simulator for high speed elevator system[J]. PCC-Osaka, 2002, 885-889.

[12] Springob,L,Holtz,J. High-Bandwidth Current Control for Torque-Ripple Compensation in PM Synchronous Machines[J]. Industrial Electronics, 2015, 45(5):713 721.

[13] Kaboli, S.; Zolghadri, M.R.; Haghbin, S.; Homaifar. Effects of the Flux Value on the Torque Ripple of the Direct Torque Controlled Induction Motor Drives Determination[J]. A Power Electronics and Drive Systems, 2013, (1): 439 - 444

[14] Quang Truong Dinh, Kyoung Kwan Ahn, Jong Il Yoon.

Volume 5 Issue 7, July 2016

\section{www.ijsr.net}




\section{International Journal of Science and Research (IJSR) \\ ISSN (Online): 2319-7064}

Index Copernicus Value (2013): 6.14 | Impact Factor (2015): 6.391

Introduction to Quantitative Feedback Theory For

Robust Force Control of Load Simulator[C].

Communications and Electronics Second International

Conference, 2008, 42 - 47

Volume 5 Issue 7, July 2016

www.ijsr.net

Licensed Under Creative Commons Attribution CC BY 